\title{
The Effectiveness of Preventive Education against Dating Violence in Japanese Agricultural and Commercial High Schools
}

\author{
Tomoko Suga1, Mayumi Shiota ${ }^{2}$ \\ ${ }^{1}$ Education Center, Rakuno Gakuen University, Hokkaido, Japan \\ ${ }^{2}$ Fukagawa-East High School, Hokkaido, Japan \\ Email: tsuga@rakuno.ac.jp
}

How to cite this paper: Suga, T. and Shiota, M. (2018) The Effectiveness of Preventive Education against Dating Violence in Japanese Agricultural and Commercial High Schools. Open Access Library Journal, 5: e4542.

https://doi.org/10.4236/oalib.1104542

Received: March 24, 2018

Accepted: April 14, 2018

Published: April 17, 2018

Copyright $\odot 2018$ by authors and Open Access Library Inc.

This work is licensed under the Creative Commons Attribution International License (CC BY 4.0).

http://creativecommons.org/licenses/by/4.0/

\section{Open Access}

\begin{abstract}
This study provided a dating violence prevention education program to 116 students ( 56 boys, 60 girls) in a vocational high school in Japan who learned mainly agriculture and business and inspected the effect. We performed a program named "A Program for Mutual Respect: Learning about Domestic Violence in Order to Value Our Relationships," which was composed of nineteen lessons over 100 minutes to do the class. Before the class, $61.0 \%$ of the students expressed little knowledge about dating violence, after the taking class, $98.3 \%$ of the students reported that it was good to know about the knowledge of dating violence. We conducted a T-test both before and directly after the class session on "Content of Violence" and compared the scores. They included content about physical, mental, sexual, and economic violence. The knowledge about the various types of violence was more meaningful after the class than before class. Our results show that dating violence prevention education was shown to be effective for the vocational high school students.
\end{abstract}

\section{Subject Areas}

Public Health

\section{Keywords}

High School Student, Dating Violence, Prevention

\section{Introduction}

Dating Violence is an early form of partner violence, occurring primarily in adolescence and early adulthood, and experienced within a "dating relation- 
ship." Domestic violence (DV) is defined as violence from a current or former partner [1]. In Japan, the most recent large-scale survey on violence from a dating partner (ages 10 to 39) was conducted by the Gender Equality Bureau Cabinet Office in 2015. In this survey, $19.1 \%$ of women and $10.6 \%$ of men reported having experienced serious violence from dating partners at least once [2]. In response to this situation, there has been greater research on dating violence in Japan. A study involving middle school students has indicated the need for preventive education against dating violence, as knowledge about dating violence can help both boys and girls to recognize behavior that is fair to their partner and also recognize violent behavior [3]. As such, an intervention study on preventive education against dating violence for male high school students was conducted. The results revealed that preventive education can help students acquire the ability to recognize coercive behavior. This demonstrated the importance of providing male high school students with preventive education against dating violence [4]. Moreover, it has been reported that DV can have negative effects on children's brains even if they merely witness verbal violence between their parents [5] [6]. An American study involving male perpetrators of DV showed that these men have a weaker ability to accurately identify sadness and fear when compared to other men, emphasizing that emotional training can lead to offender rehabilitation [7].

Considering that a DV home environment in one's childhood has a negative effect on the brain and the ease of offender rehabilitation, I believe that preventive education against dating violence for middle and high school students is an important tool for eradicating DV at home. One study has demonstrated the effectiveness of preventive education against dating violence for Japanese male high school students, but since there are a variety of types of high schools in Japan, this study is concerned with the effectiveness of preventive education against dating violence for students at vocational high schools that specialize in agriculture or business. As such, we asked questions about physical violence, mental violence, and financial violence, as well as the specific acts of physical violence (kicks, Yells, etc.) to elucidate the effectiveness of preventive education.

\section{Methodology}

\subsection{Participants}

The study comprised 116 participants (56 boys, 60 girls) living in the Hokkaido region in Japan, who were in their first, second, or third year of high school in December 2017. I requested research cooperation from the principal of the high school. Specifically, they were students at vocational high schools, where they were acquiring technical skills in agriculture or business. Most students from such schools find employment after graduation.

\subsection{Survey}

Two questionnaires, "Preliminary Question about Dating Violence" (Table 1) 
Table 1. Preliminary question about dating violence.

1) I know about dating violence.

2) I think dating violence is relevant to my life.

3) I want to know about dating violence

Yes $=4$ points, somewhat $\mathrm{Yes}=3$ points, somewhat $\mathrm{No}=2$ points, $\mathrm{No}=1$ point.

Table 2. Content of violence.

1) Beats or kicks

2) Yells or screams

3) Ignores for a long time

4) Restricts relationships with friends and checks email

5) Dating expense are always paid

6) Does not cooperate with contraception

Violence $=4$ points, somewhat violence $=3$ points, not so violence $=2$ points, not violence $=1$ point .

and "Contents of Violence." Table 2 was administered to all 116 high school students. "Preliminary Question about Dating Violence" were asked to assess high school students' knowledge of dating violence and the "Content of Violence" question were used to check the high school students' view on four kinds of violence (physical, mental, financial, sexual).

\subsection{Dating Violence Prevention Education Program for High School Students. Revised Edition (Adapted from Suga, 2017)}

I revised the Dating Violence Prevention Education Program for High School Students (Suga, 2017), by adding four parts,: Lesson 14 "Why Do Victims Not Escape?"; Lesson 15 "Learned Helplessness"; Lesson 16 "Learned Helplessness Fits Dating Victims."; Lesson 17 "The Person Who Experienced Fear." This program is based on situations that actually happen in schools and is designed to have content that is easily understood by Japanese high school students. The main objective of the program was to communication that when people respect each other, there would be less violence or dating violence; therefore, I named it, "A Program for Mutual Respect: Learning about Domestic Violence in Order to Value Our Relationships.” This program is composed of nineteen lessons (Table 3).

Lesson 1, "Meeting People," provides students with an introduction to human relationships by discussing how feelings like "I'm glad I met this person." or "Being with this person makes me tired" are all normal, and that these feelings are important.

Lesson 2, "What Does It Mean to Respect Others?" students discussed in class things their friends have said to them that made them feel good.

Lesson 3, "What Kind of Person Can't Respect Others?", we discussed how disrespectful people constantly comment on the flaws in others, never try to use their words to explain things clearly, or use physical or verbal abuse to get their 
Table 3. Content of the dating violence prevention educational program (revised edition).

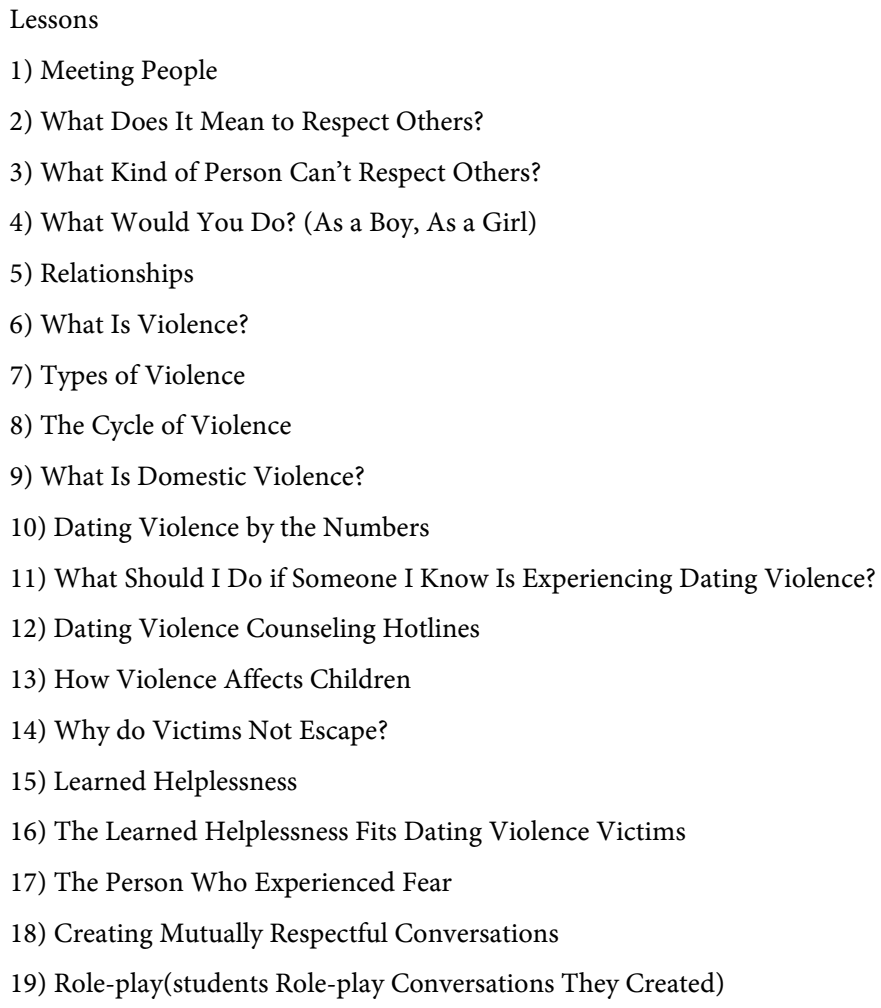

own way emotionally.

Lesson 4 includes narrative examples of dating violence happening among young people. Two stories were presented. In one boy abuser deliberately kicked a girl's bicycle in order to coerce her. In the other, a boy abuser grabs another boy's phone and checks his usage history. I presented both sides to show that both boys and girls are capable of being abusers, and both boys and girls are capable of becoming victims.

Lesson 5, "Relationships," Focuses on how it is all right to "be yourself" and on how people need to learn how to maintain the appropriate amount of distance.

Lesson 6, "What Is Violence?" teaches that the essence of violence is control. Violent people tend to deny their violence or make light of its effects.

Lesson 7, "Types of Violence," instructors list and explain different types of violence and abuse including, physical, psychological, sexual, and economic abuse.

Lesson 8 covers the "Cycle of Violence". The Acute Battering Incident is where violence occurs. After this incident, abusers feel a sense of relief from tension, causing them to apologize and behave kindly to the victims in what is referred to as the Honeymoon Phase. However, this in turn leads to the Tension Building Phase, leading to another violent incident. Instructors explain that this pattern is dating violence.

Lesson 9, "What Is Domestic Violence?" the instructors specifically define 
dating violence. It is violence perpetrated by one member in an intimate relationship (such as a spouse or a lover) against another. Students are told that in this type of violence, as the relationship becomes stronger, and the more severe the abuse becomes.

Lesson 10, "Dating Violence by the Numbers," Students are told that in a 2012 study by the Japanese government, $29.1 \%$ of women and $15.6 \%$ of men reported that they had been brutally abused at least once. This is to help students understand using statistics that dating violence is something that can happen close to home.

Lesson 11, "What Should I Do if Someone I Know Is Experiencing Dating Violence?" explains that dating violence is not something that you should ignore as well as how to notice that the abuse is taking place.

Lesson 12 introduces Japan's Dating Violence Counseling Hotlines.

Lesson 13, "How Violence Affects Children," some children who are victims of dating violence or other abuse to go on to become victims or perpetrators of violence later in life. However, providing care for these children can break of abuse.

Finally, in Lesson 18, "Creating Mutually Respectful Conversations," and Lesson 19 "Role-play," students create conversations themselves and role play them with the class, which is designed to foster empathy among participants. In terms of the lesson format, they were taught with a combination of lectures with open discussions on the students' role-plays.

\subsection{Research Design (Figure 1)}

The design of this research is shown in Figure 1. The study ran from November 2017 to December 2017, and included 116 students (56 boys, 60 girls) from the Hokkaido region of Japan who were in their first, second or third year of high school with a major in Agriculture or Commercial. Prior to the class, students completed the "Preliminary Question about Dating Violence" (Table 1), and the "Content of Violence" (Table 2) questionnaires. Following the class, students completed two questionnaires including a post-class survey of the "Content of Violence" and the "Post -Class Question about Dating Violence" (Table 4). The

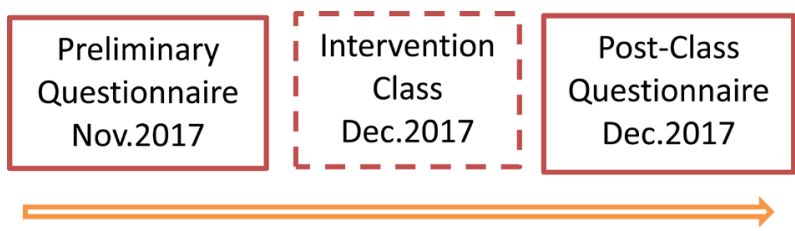

Figure 1. Research design.

Table 4. Post-class question about dating violence.

1) It was good to learn about dating violence.

2) After the class, I think dating violence is relevant to my life.

Yes $=4$ points, somewhat $\mathrm{Yes}=3$ points, somewhat $\mathrm{No}=2$ points, No $=1$ point 
"Content of Violence" questionnaire was conducted twice by students, once before class and directly after class. We measured the effect of dating violence prevention class by the "Content of Violence" questionnaire. The class underwent a one-time, 100 minute class.

\subsection{Data Analysis}

Descriptive statistics on the three questionnaires were calculated. In order to measure the effect of the dating violence class, I performed T-test for the before and directly after class "Content of Violence" comparisons. I used IBM SPSS 22.0 .

\subsection{Ethical Considerations}

This study was conducted with the permission of the Rakuno Gakuen University Research Ethics Committee. Before seeking consent for participation in this study, I explained everything about the study to the students. Before they participated, I obtained written consent. The seven questionnaires were confidential, and came with a written explanation that participation in the study was voluntary. The questionnaires clearly stipulated that any data provided would not be used for any purpose outside of this research study. Further, the dating violence prevention class was conducted during the special education period. I personally administered and collected the questionnaires before and directly after the class.

\section{Results}

\subsection{Preliminary Question about Dating Violence (Figures 2-4)}

On the first item that asked, "I know about dating violence," $61.0 \%$ answered either "Somewhat No" (29.3\%) or "No" (31.7\%). On Question 2 "I think dating violence is relevant to my life," 67.5\% answered either "Somewhat Yes" (32.5\%) or "Yes" (35.0\%). On Question 3 "I want to know about dating violence," $62.3 \%$ answered either "Somewhat No" $(40.2 \%)$ or "No" (22.1\%). Students may not know the specifics of dating violence, but they do believe that it is relevant to their lives. However, students also reported limited interest in learning about

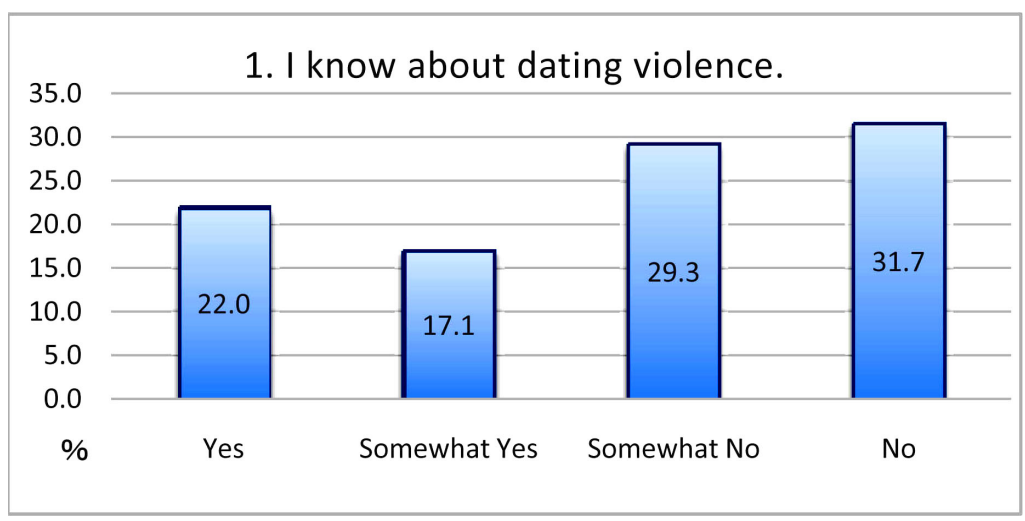

Figure 2. I know about dating violence. 


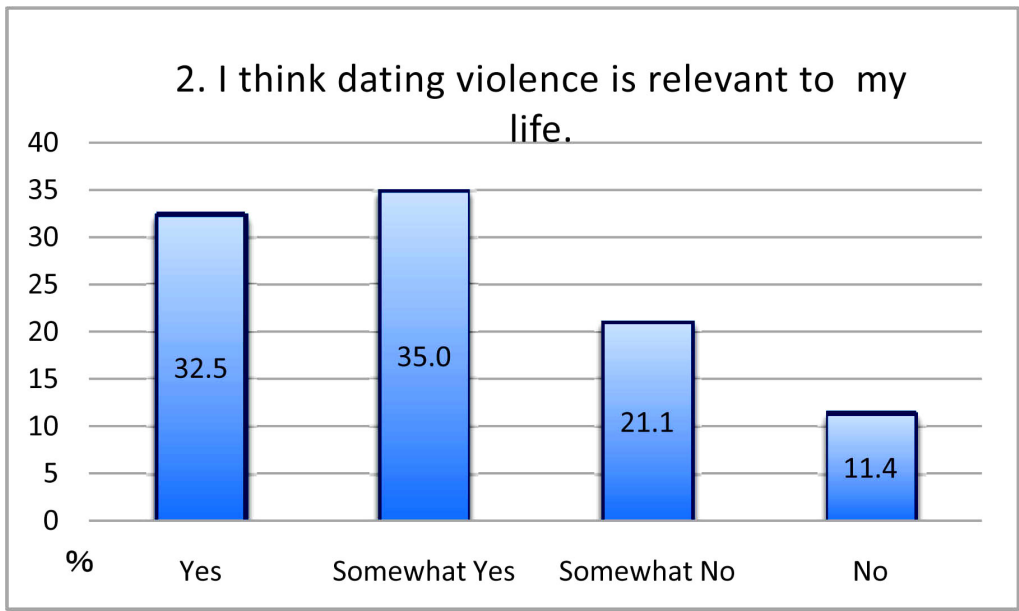

Figure 3. I think dating violence is relevant to my life.

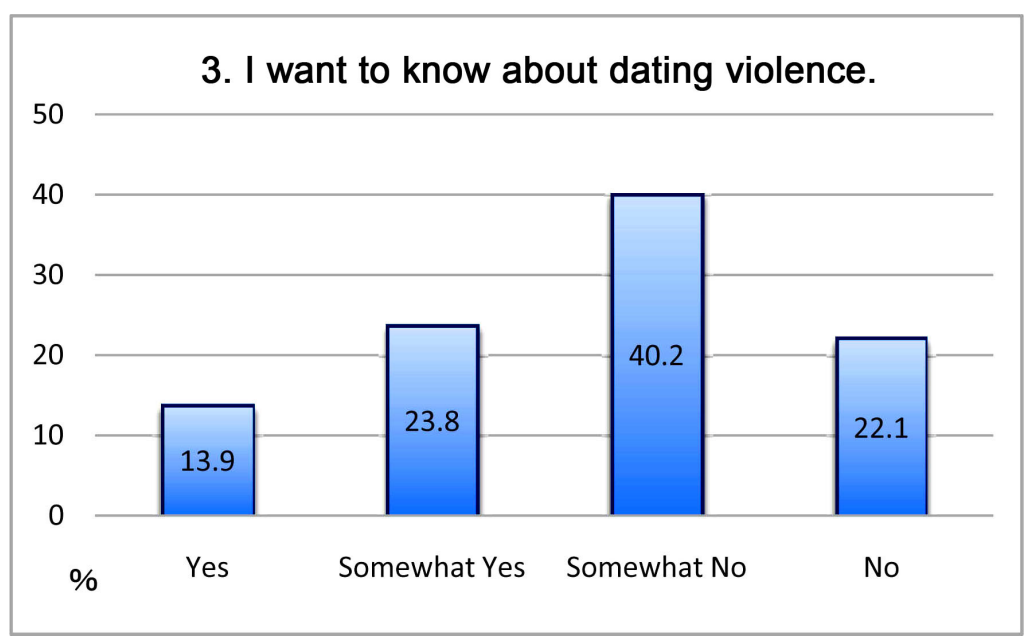

Figure 4. I want to know about dating violence.

dating violence.

\subsection{Dating Violence Prevention Intervention Comparison before and after Class}

The word "data" is plural, not singular. I conducted a t-test for effectiveness measurement on items 1 - 6 of concrete forms of violence (Table 2).

For "1. Beats or kicks," the result was $3.70 \pm 0.78$ (ave. \pm SD) before intervention and $3.87 \pm 0.43$ after intervention, showing a significant difference $(\mathrm{p}<$ 0.05) (Figure 5).

For "2. Yells or screams," the result was $2.84 \pm 0.92$ before intervention and $3.22 \pm 0.58$ after intervention, showing a significant difference $(\mathrm{p}<0.001)$ (Figure 6).

For "3. Ignores for a long time," the result was $2.54 \pm 0.97$ before intervention and $3.32 \pm 0.88$ after intervention, showing a significant difference $(\mathrm{p}<0.001)$ (Figure 7).

For "4. Restricts relationships with friends and checks email," the result was 
$2.87 \pm 1.05$ before intervention and $3.51 \pm 0.79$ after intervention, showing a significant difference $(\mathrm{p}<0.01)$ (Figure 8).

For "5. Dating expenses are always paid," the result was $3.05 \pm 0.98$ before intervention and $3.69 \pm 0.57$ after intervention, showing a significant difference ( $\mathrm{p}$ $<0.001$ ) (Figure 9).

For "6. Does not cooperate with contraception," the result was $3.23 \pm 0.94$ before intervention and $3.72 \pm 0.62$ after intervention, showing a significant difference $(\mathrm{p}<0.001)$ (Figure 10).

\subsection{Post-Class Questions about Dating Violence}

(Figure 11, Figure 12)

The results of the questionnaire immediately after the intervention class were as follows. For the statement " 1 . It was good to learn about dating violence," $71.6 \%$

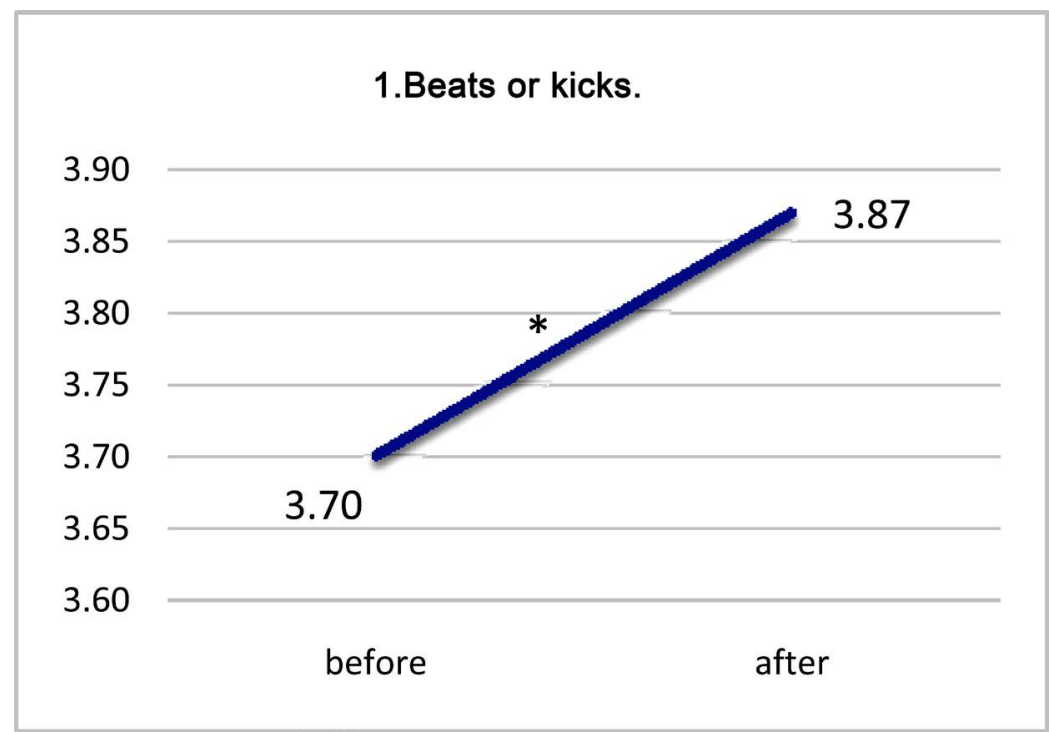

Figure 5. Beats or kicks.

\section{Yells or screams.}

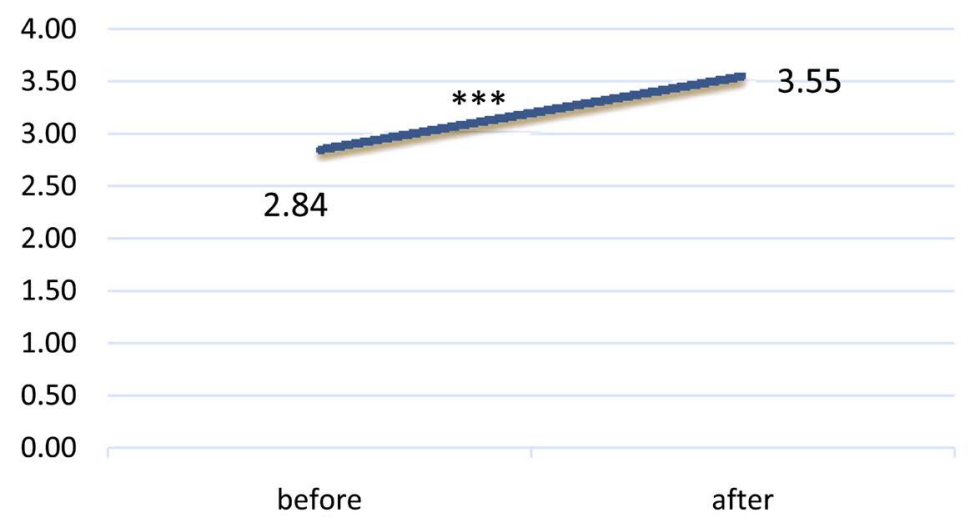

Figure 6. Yells or screams. 
3. Ignores for a long time.

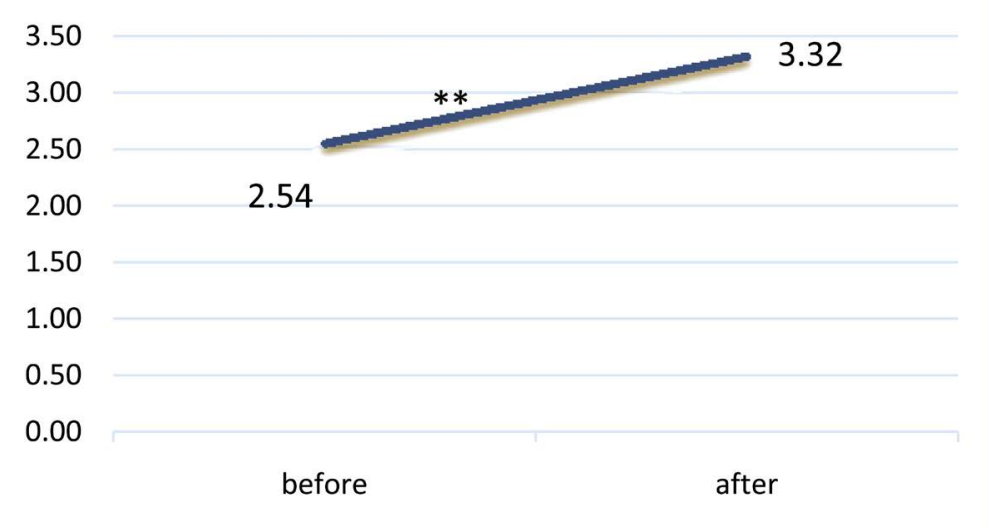

Figure 7. Ignores for a long time.

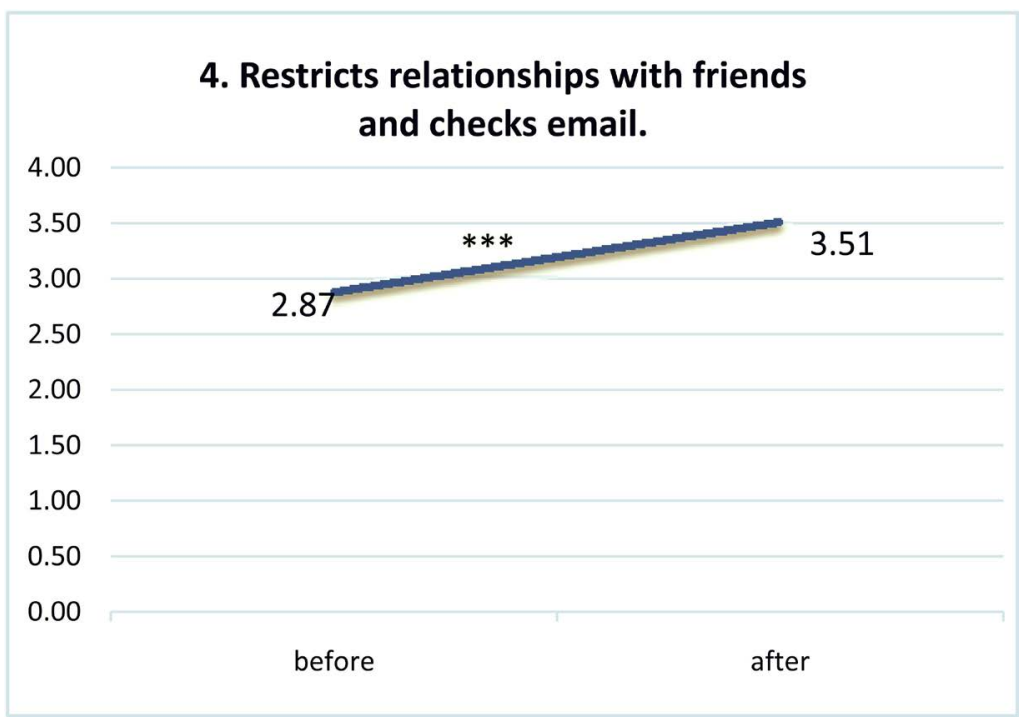

Figure 8. Restricts relationships with friends and checks email.

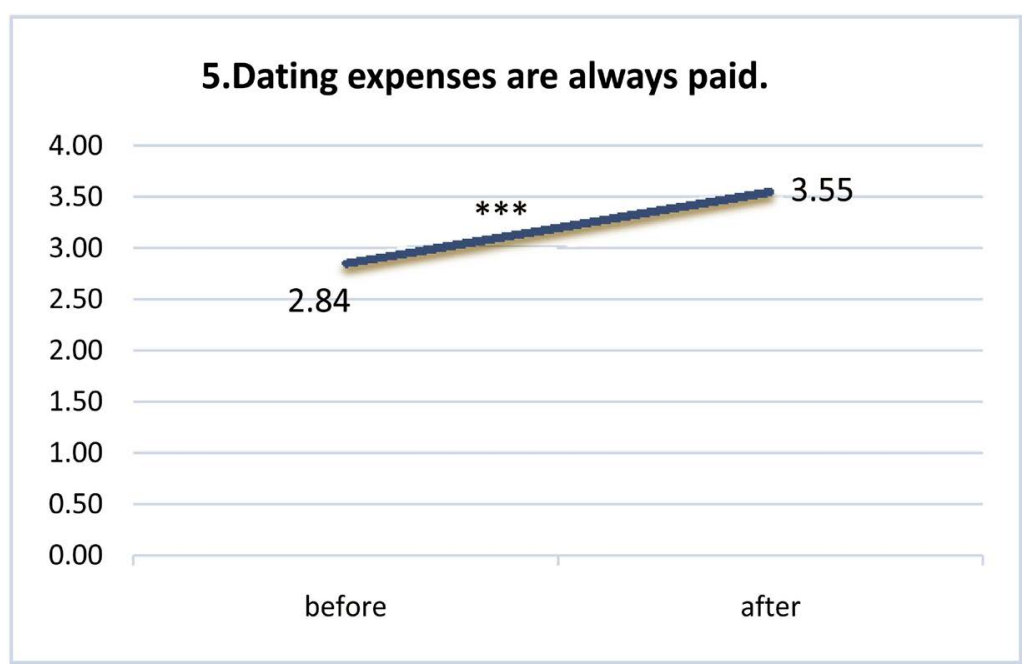

Figure 9. Dating expenses are always paid. 


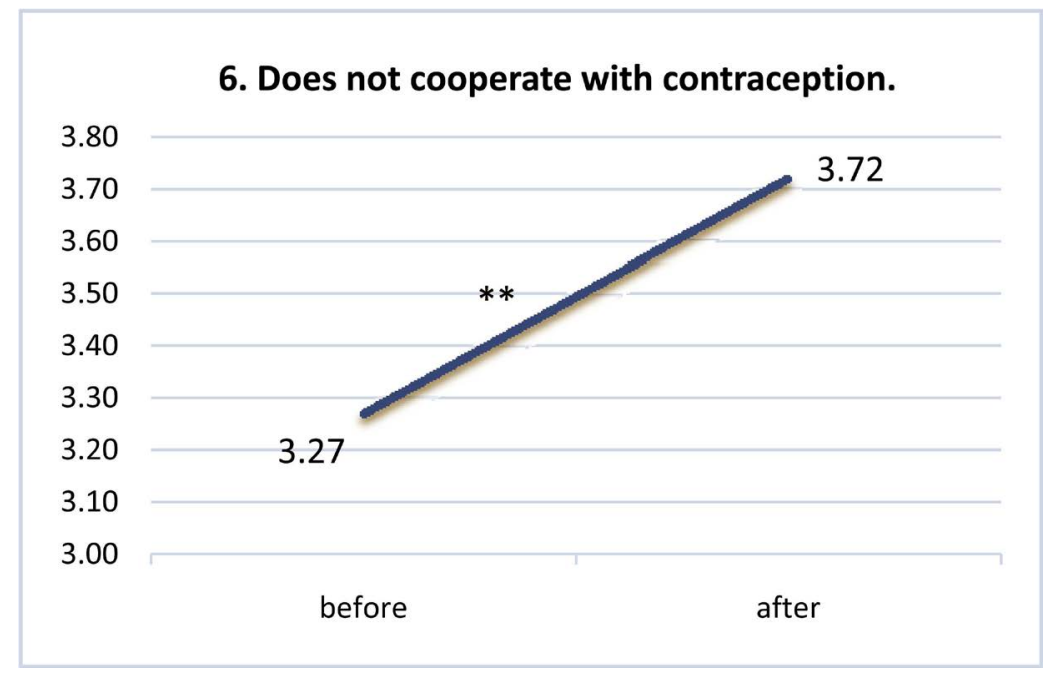

Figure 10. Does not cooperate with contraception.

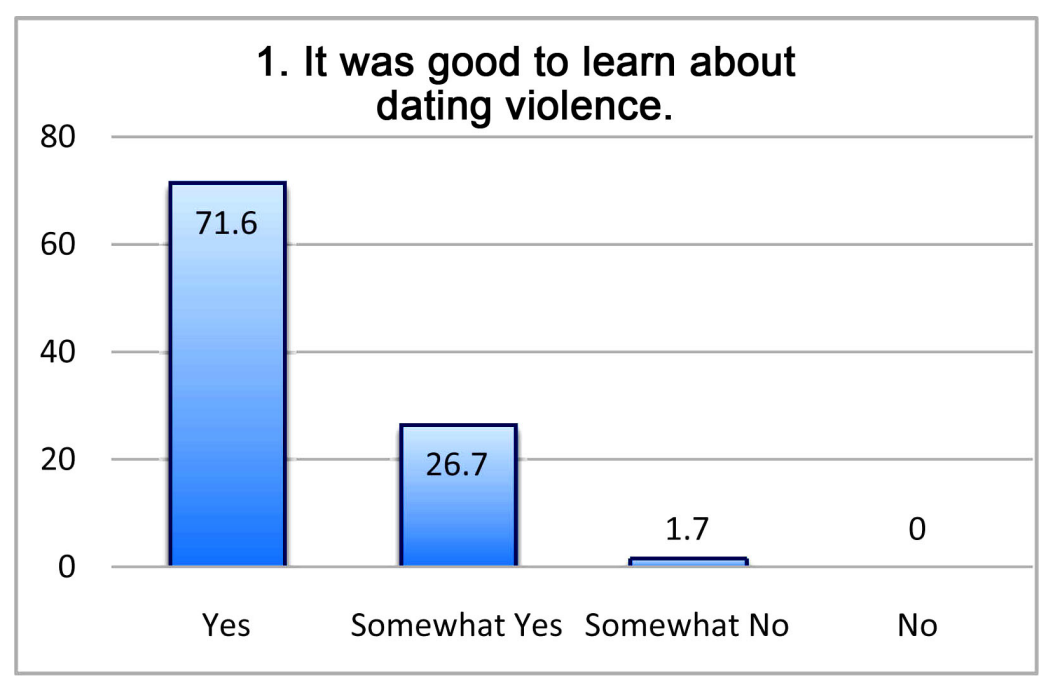

Figure 11. It was good learn about dating violence.

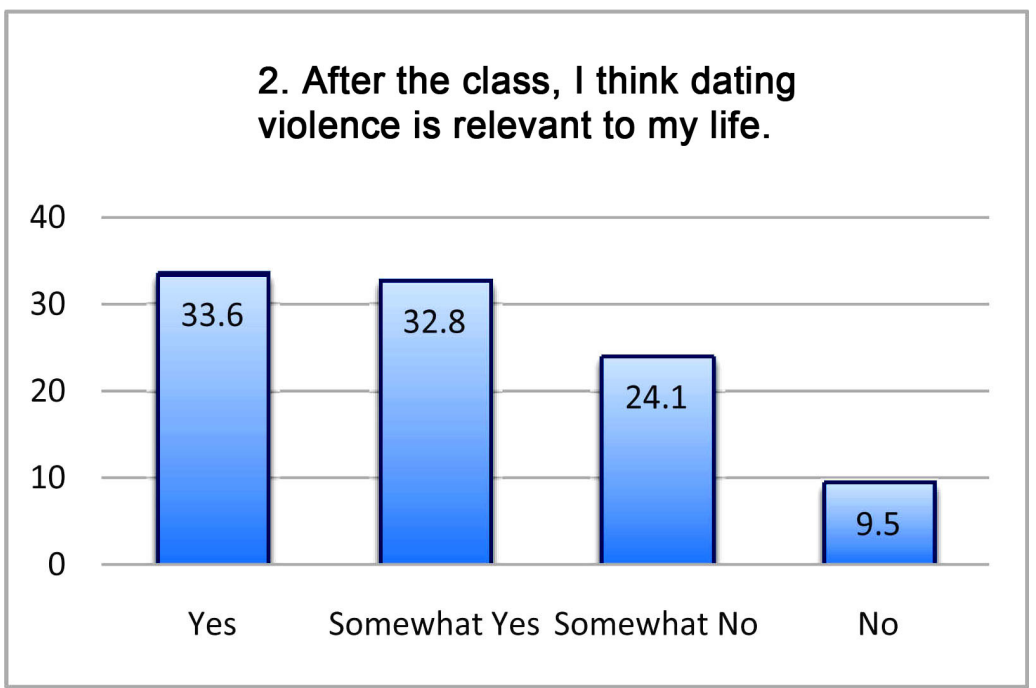

Figure 12. After the class, I think dating violence is relevant to my life. 
of the high school students answered "Yes," and 26.7\% answered "Somewhat Yes," meaning that $98.3 \%$ thought it was good that they had learned about dating violence (Figure 11). For the statement " 2 . After the class, I think dating violence is relevant to my life," 66.4\% (33.6\% "Yes" and 32.8\% "Somewhat Yes") thought that dating violence was something that concerned them, while $34.6 \%$ thought that it did not concern them (Figure 12).

\subsection{Post-Class Comments}

Common comments included, "Now I know about dating violence, so I will try to be careful and be aware of what I learned today, if I see signs of it in the future," "I thought dating violence had nothing to do with me, but listening to the lecture made me realize it is relevant," "If I end up fighting with my partner, I want to solve it through communication," "I learned that it is best to break up if my partner is violent toward me," and "I came to understand very well that asking for help can protect me." Moreover, there were also some students that came to harbor doubts about their own family situations based on what they had heard in the lecture, writing comments like "I can't stand my parents fighting and hope that they will break up. If I get married, I won't hit my partner," and "I want to be able to tell my family exactly what I feel."

\section{Discussion}

The aim of this intervention study was to measure the effectiveness of preventive education against dating violence at high schools that specialize in agriculture or business. These are vocational high schools whose students acquire agricultural and business skills, most of whom find employment after graduation. As these were public vocational high schools, many of the students' families were not financially well-off. Considering these factors, I thought there would be a need for a class with preventive education against dating violence for these high school students. For the statement "I know about dating violence" in the pre-class survey, $61.0 \%$ of the students responded that they did not know about it. It is concerning that there are so many high school students without knowledge about dating violence. I have not found any research on victims of dating violence that is limited to Japanese high school students, but a survey on Ethiopian female high school students showed that $62.2 \%$ had suffered physical, sexual, and mental violence [8]. An American survey revealed that $9.44 \%$ of 12-year-old high school students (all ethnicities) had suffered physical violence from a partner. In the United States, the victim rate differs depending on ethnicity, with the highest rate for African Americans, followed by Hispanics, Asians, and whites [9]. Thus, the victim rate of dating violence differs depending on country and ethnicity, but it appears certain that high school victims exist in all countries. Furthermore, for the statement "2. I think dating violence is relevant to my life," $67.5 \%$ of students responded that it does concern them. This suggests that they are affected, but that they have lacked 
the opportunity to educate themselves. However, for the statement " 3 . I want to know about dating violence," $62.3 \%$ of students responded that they do not want to know about it. The intervention class was conducted with the participation of such high school students. As for the class contents, I broached the topic of dating violence by talking about mutual respect, delivering a 60-minute lecture containing elements including "What is violence?" "Violence can be categorized as physical, mental, financial, and sexual," "The cycle of violence," "What is domestic violence and dating violence?" "What should you do if you become a victim of DV?" "DV phone consultations," and "Why doesn't the victim run away?" As compared to the pre-class survey, the post-class survey showed a significant increase in the number of students recognizing all six forms of violence: 1. Beats or kicks, 2. Yell, 3. Ignore for a long time, 4. Restrict friendships and check e-mail, 5. Pay for all dating expenses, and 6. Do not cooperate in the use of contraception. From this, it became clear that even one class can have the effect of allowing students without knowledge about dating and DV to acquire that knowledge. In fact, for the statement "1. It was good to know about dating violence" in the post-class survey, $98.3 \%$ of the students responded that it was good that they had learned about dating violence. For the statement " 2 . After the class, I thought about how dating violence is related to me," $66.4 \%$ recognized that dating violence was something that concerns them. Considering that $67.5 \%$ responded in the same way before the class, it seems that none of the students came to the realization that dating violence is relevant to them as a result of the class.

This intervention study showed that the form of preventive education against dating violence in Japan was effective, and in particular, that it had the effect of helping students further understand the specific forms of dating violence. The contribution of this research is that $98.3 \%$ of the students responded that it was good that they had learned about dating violence after the class. I surveyed American papers on the topic and found four preventive education programs: Safe Dates [10], the Fourth R [11], Shifting Boundaries [12], and Coaching Boys into Men [13]. Each of these was reported to be effective for high school students. Considering the results of this study, as well as the intervention results of the American preventive education programs, I believe it is necessary to conduct preventive education against dating violence at least once during the middle school or high school years, regardless of country. The prevention education program should include topics of "the cycle of violence" and "physical, mental, financial, and sexual violence" from all countries.

One limitation of this research is that it does not show how long the new-found knowledge lasts; there is no way to know from this particular study how much the students will remember about dating violence after one, five, or ten years. That kind of follow-up is beyond the scope of this study. However, it seems that the preventive education held practical significance, and the results this program have academic significance. 


\section{Conclusion}

In Japan, we were faced with a situation where $61.0 \%$ of students at vocational high schools that specialize in agriculture or business did not know about dating violence. However, immediately after the intervention class, $98.3 \%$ of students responded that it was beneficial for them to have learned about dating violence. Moreover, a statistical comparison of pre-and post-intervention responses demonstrated the intervention's effectiveness for increasing the students' knowledge about physical, mental, financial, and sexual violence. As such, we need to keep in mind the lack of knowledge about dating violence among high school students and conduct preventive education.

\section{Acknowledgements}

This work was supported by JSPS KAKENHI Grant Number JP18K18294.

\section{References}

[1] World Health Organization (2013) Responding to Intimate Partner Violence and Sexual Violence against Women. WHO Clinical and Policy Guidelines, 1-55. http://www.who.int/reproductivehealth/publications/violence/

[2] Gender Equality Bureau Cabinet Office (2015) Gender Equality in Japan Basic Data, 36-49. http://www.gender.go.jp

[3] Nagamatsu, M., Hamada, Y. and Hara, K. (2016) Factors Associated with Recognition of the Signs of Dating Violence by Japanese Junior High School Students. Environmental Health and Preventive Medicine, 21, 9-17. https://doi.org/10.1007/s12199-015-0491-1

[4] Suga, T. (2017) Results of Dating Violence Prevention Education for Japanese High School Boys. Open Journal of Social Sciences, 5, 173-185. https://doi.org/10.4236/jss.2017.512013

[5] Tomoda, A., Polcari, A., Anderson, C.M. and Teicher, M.H. (2012) Reduced Visual Cortex Gray Matter Volume and Thickness in Young Adults Who Witnessed Domestic Violence during Childhood. PLOS ONE, 7, e52528. https://doi.org/10.1371/journal.pone.0052528

[6] Tomoda, A., Sheu, Y.-S., Rabi, K., Suzuki, H., Navalta, C.P., Polcari, A. and Teicher, M.H. (2011) Exposure to Parental Verbal abuse Is Associated with Increased Gray Matter Volume in Superior Temporal Gyrus. Neuroimage, 54, S280-S286. https://doi.org/10.1016/j.neuroimage.2010.05.027

[7] Nyline, B., Softas-Nall, L., Peterson, E., Peake, M. and Woods, C.J. (2018) Inaccuracies in Facial Recognition of Fear and Sadness for Male Domestic Violence Offenders. Open Journal of Social Sciences, 6, 37-51. https://doi.org/10.4236/jss.2018.62004

[8] Letta, T., Feleke, A. and Derseh, L. (2014) Assessment of Violence and Associated Factors among Rural High School Female Students, in Hadiya Zone, Southern Nation and Nationalities Peoples' Region, Ethiopia, 2013. Open Access Library Journal, 1, e659.

[9] Rothman, E.F. and Xuan, Z. (2014) Trends in Physical Dating Violence Victimization among U.S. High School Students, 1999-2011. Journal of School Violence, 13, 277-290. https://doi.org/10.1080/15388220.2013.847377

[10] Foshee, V.A., Bauman, K.E., Ennett, S.T. Suchindran, C., Benefield, T. and Linder, 
G.F. (2005) Assessing the Effects of the Dating Violence Prevention Program "Safe Dates" Using Random Coefficient Regression Modeling. Prevention Science, 6, 245-258. https://doi.org/10.1007/s11121-005-0007-0

[11] Wolfe, D.A., Crooks, C., Jaffe, P., Chiodo, D., Hughes, R. and Ellis, E. (2009) A School-Based Program to Prevent Adolescent Dating Violence: A Cluster Randomized Trial. Archives of Pediatrics \& Adolescent Medicine, 163, 692-699.

https://doi.org/10.1001/archpediatrics.2009.69

[12] Taylor, B.G., Stein, N. and Burden F.F. (2010) Exploring Gender Differences in Dating Violence/Harassment Prevention Programming in Middle Schools. Journal of Experimental Criminology, 6, 419-445.

https://doi.org/10.1007/s11292-010-9103-7

[13] Miller, E., McCauley, H., Virata, M.C., Decker, M., Tancredi, D. and Moideen, F. (2010) Coaching Boys into Men: Preliminary Success of a Sexual Violence Prevention Program. Journal of Adolescent Health, 48, S85-S86.

https://doi.org/10.1016/j.jadohealth.2010.11.179 